\title{
Intranasal dexmedetomidine and intravenous ketamine for procedural sedation in a child with alpha- mannosidosis: a magic bullet?
}

\author{
Matteo Trevisan ${ }^{1}$, Sara Romano ${ }^{1 *}$ (D), Egidio Barbi ${ }^{1,2}$, Irene Bruno ${ }^{2}$, Flora Maria Murru ${ }^{3}$ and Giorgio Cozzi ${ }^{4}$
}

\begin{abstract}
Background: Procedural sedation is increasingly needed in pediatrics. Although different drugs or drugs association are available, which is the safest and most efficient has yet to be defined, especially in syndromic children with increased sedation-related risk factors.

Case report: we report the case of a five-year-old child affected by alpha-mannosidosis who required procedural sedation for an MRI scan and a lumbar puncture. We administered intranasal dexmedetomidine $(4 \mu \mathrm{g} / \mathrm{kg}) 45 \mathrm{~min}$ before intravenous cannulation, followed by one bolus of ketamine $(1 \mathrm{mg} / \mathrm{kg})$ for each procedure. The patient maintained spontaneous breathing and no desaturation or any complication occurred.
\end{abstract}

Conclusion: intranasal dexmedetomidine and intravenous ketamine could be a feasible option for MRI and lumbar puncture in children with alpha-mannosidosis needing sedation.

Keywords: Dexmedetomidine, Ketamine, Procedural sedation, Alpha-mannosidosis

\section{Introduction}

Procedural sedation is an emerging cornerstone in pediatrics aiming to control pain, decrease fear and emotional response when immobility is required or during painful procedures. The ideal sedative drug should have a prompt onset of action, be easy to administer, with a short elimination half time, offering efficacious pain relief without side effects. Particular attention is required when procedural sedation is needed in patients with disabilities associated with specific genetic disease or neurologic impairment. These patients present reduced communicative and expressive skills which reduce pain recognition and cooperation and they experience more pain and distress when compared to healthy peers [1]. Therefore, they are frequently candidates for sedation, which is a challenge due to their comorbidities, which cause increased sedation-related risk. For example,

\footnotetext{
*Correspondence: sara.romano17@gmail.com

'Department of Medicine, Surgery, and Health Sciences, University of Trieste, Trieste, Italy

Full list of author information is available at the end of the article
}

children affected by storage diseases usually present higher risks due to hypotonic pharynx and soft tissue thickness, neck stiffness, atlantooccipital instability and cardiopathies. They are predisposed to serious anesthetic complications, such as airway collapse with challenging airway management and respiratory depression with difficult ventilation and oxygenation. In addition, their atlanto-occipital instability can lead to spinal compression and subsequent paralysis. In these fragile patients, anesthetic drugs such as propofol and midazolam can facilitate cardio-respiratory complications even within standard doses, affecting respiratory drive and airway shape. For this reason, the association of dexmedetomidine and ketamine, maintaining active upper respiratory reflexes and minimally impacting on airway shape, could allow safer sedation.

Finally, venous access may be troublesome, scaring and painful for these children, who often require repeated hospital admissions and procedures, so that a sedation sequence based on an intranasal premedication,

(c) The Author(s). 2019 Open Access This article is distributed under the terms of the Creative Commons Attribution 4.0 International License (http://creativecommons.org/licenses/by/4.0/), which permits unrestricted use, distribution, and 
facilitating cannulation without putting the patient at risk, may offer further advantages.

\section{Case report}

We report the case of a five-year-old child, affected by alpha-mannosidosis requiring a brain magnetic resonance (MRI) and a lumbar puncture during a planned follow-up for his enzymatic substitutive treatment. He had received a genetic diagnosis, showing mutation of the gene MAN2B1, because of coarse facial features and mild mental retardation. In addition, he developed psychomotor and speech retardation, recurrent respiratory infections, inguinal hernia, vertebral body listhesis and bilateral neurosensorial deafness. No hepatic, splenic, cardiac or bone marrow involvement were detected. Because of the difficult airway management and a history of snoring sleep, notwithstanding a previous adenotonsillectomy procedure, we decided to associate ketamine and dexmedetomidine for the procedural sedation. Clear fluids were offered up to 2 hours before the procedure. $90 \mathrm{~min}$ before the scheduled cannulation, the child received a topical anesthetic cream on two possible sites and 45 min before the cannulation attempt, intranasal dexmedetomidine $(4 \mu \mathrm{g} / \mathrm{kg}$ by mean of a Mucosal Atomizing Device) was administered. The emla cream was removed 20 min before the cannulation attempt, in order to avoid stimulating the child by stripping the dressing from the skin just before venipuncture, targeting a good sedation level before the puncture.

This premedication allowed to perform a painless and fearless intravenous access. A bolus of intravenous ketamine $(1 \mathrm{mg} / \mathrm{Kg})$ was administered twice, before both procedures, to diminish the estimated risk of about $30 \%$ of sedation failure with dexmedetomidine alone for MRI [2] and the expected lumbar puncture's pain.

The patient was monitored with end-tidal carbon dioxide $\left(\mathrm{EtCO}_{2}\right)$ nasal cannula and pulse oximetry. During the MRI scan the patient lied down with the head slightly rotated to achieve the best airways' patency, maintaining spontaneous breathing without desaturations or complications $\left(\mathrm{SpO}_{2}\right.$ 95-98\%, HR 93-97 and $\left.\mathrm{EtCO}_{2} 40-45\right)$.

Findings of the MRI evaluation showed a very narrow air column in the larynx and pharynx space, confirming the high risk of an upper respiratory collapse (Fig. 1.) The child did not require supplemental oxygen or any intervention. Further, he underwent lumbar puncture after administration of another bolus of ketamine at the same dose, lying on a side, without any complication. Both procedures lasted a total of $55 \mathrm{~min}$ and an hour after, the patient awoke in a well-appearing state.

\section{Discussion}

While sedation in high-risk patients should be managed only by experienced pediatric anesthesiologists or

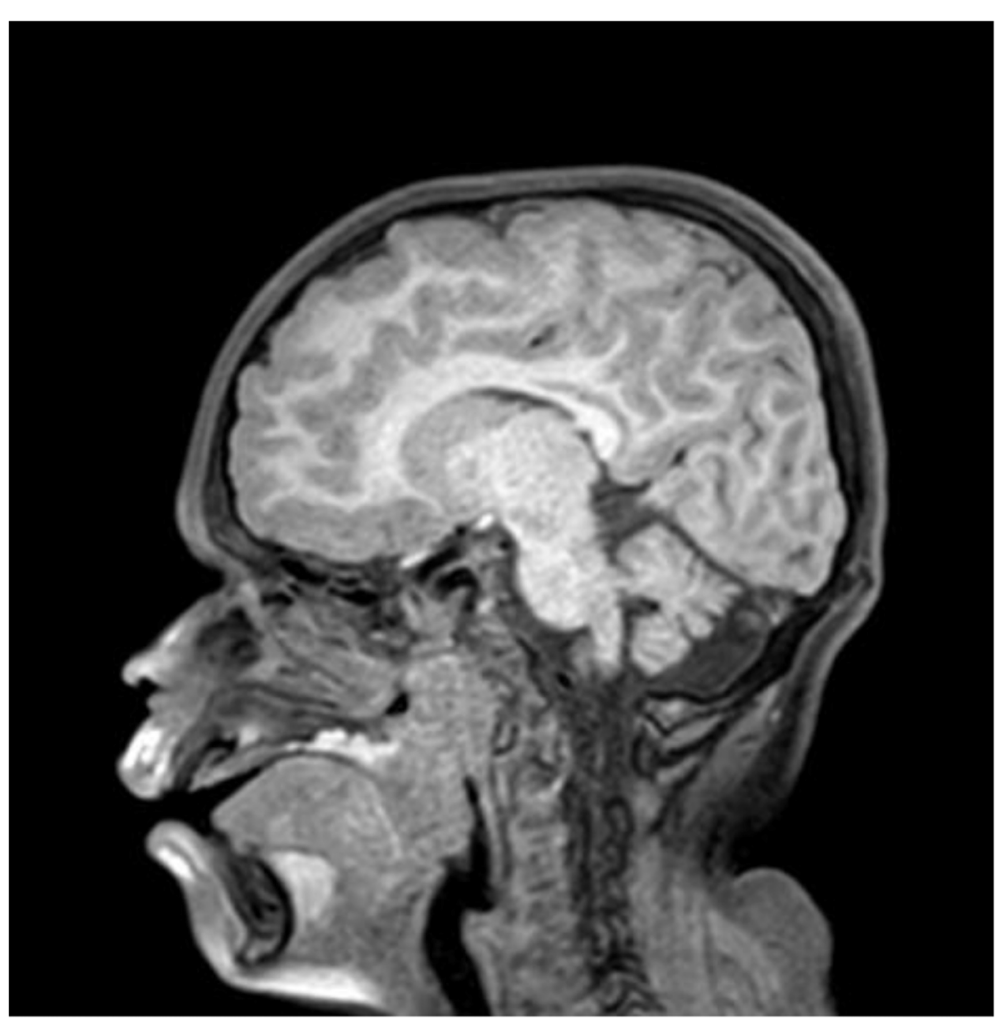

Fig. $1 \mathrm{MRI}$ scan showing a very narrow air column in the larynx and pharynx space along with the significant adenotonsillay hypertrophy 
intensivists, the association of dexmedetomidine and ketamine has already been reported as a highly efficacious and safe option also in the setting of procedural sedation for children without risk factors, in the general perspective of adequately trained and skilled pediatric sedation providers.

Alpha-mannosidosis is a rare autosomal recessive lysosomal storage disorder with an estimated prevalence of one in 500,000-1,000,000 live births [3]. A decreased alpha-mannosidase activity results in impaired glycoprotein degradation in the lysosomes, as well as compromised cellular function and apoptosis [4]. The high prevalence of airway obstruction and restrictive pulmonary disease, cardiac impairment and cervical spine issues put these patients to a high anesthetic risk. The upper airways can be narrowed due to the accumulation of mannose-rich oligosaccharides causing macroglossia, adenotonsillary hypertrophy and thickened soft tissues in the laryngopharynx. Other typical features are deformities of the skull or spine, flattened nasal bridge, short neck, high anterior larynx, mandibular abnormalities or abnormal cervical vertebrae [5]. Aiming to limit any possible effects on respiratory functions, dexmedetomidine and ketamine constitute a good combo.

Ketamine is a dissociative and sedative drug, frequently used for painful procedures, because of its potent analgesic and amnestic effect with minimal respiratory or circulatory depression [6]. It can be administered either via intravenous, intramuscular, intranasal or oral routes. Nevertheless, the oral and intranasal ways display a low bioavailability and, in order to achieve adequate sedation, much higher doses are required [7]. Most common side effects are mild hypertension and tachycardia, emesis (8-25\%), hypersalivation, hallucination, psychotomimetic effect $(7 \%)$ and laryngospasm (0.3\%) [8]. Such adverse effects can be managed with administration of ondansetron for vomiting and positive airway pressure to overcome laryngospasm. Hypersalivation usually is self-limited, not requiring any medication [9]. Ketamine, when used by pediatricians, has an impressive safety record in the literature and should be considered as a standard of care in the pediatric emergency department [10].

Dexmedetomidine is $\alpha_{2}$-adrenoreceptor agonist that induces sedation, anxiolysis and mild analgesia, without respiratory depression [11]. Its main side effects are bradycardia and hypotension, usually not requiring any medication. While the intravenous administration is more used in pediatric intensive care, it has been demonstrated that the intranasal route has a good bioavailability, decreasing children's pain and distress and inducing sedation as an effective premedication [12, 13]. Prophylactic use of atropine should be avoided when using dexmedetomidine, due to the high risk of blood pressure hypertension [14].
The most frequently used premedication sedative in children is midazolam. Midazolam has untoward side effects such as paradoxical reactions, respiratory depression in patients with specific risk factors, amnesia and unpleasant taste. Moreover, when it is administered via intranasal route, many patients complain of nasal burning and gagging even after lidocaine premedication. Dexmedetomidine is an odorless, colorless and tasteless solution, its intranasal use is painless and could be an innovative approach for pediatric premedication, in particular for a successful venous cannulation [15]. As a matter of fact, a meta-analysis of thirteen randomized controlled trials about premedication with dexmedetomidine in pediatric patients revealed the superiority of the latter on midazolam in promoting preoperative sedation and decreasing postoperative pain [16]. Intranasal dexmedetomidine, when used as the sole sedative drug for pediatric MRI, requires a rescue treatment in $30 \%$ of cases. When intranasal dexmedetomidine is associated with oral midazolam $(0.5 \mathrm{mg} / \mathrm{kg})$ the success rate significantly increases, but still at the age of 5 years, a $10 \%$ of patients will require an additional treatment to adequately perform MRI imaging [2].

As for ketamine, substantial data about safety of non-anesthesiologist managed dexmedetomidine are available $[17,18]$.

Several authors proposed dexmedetomidine and ketamine as a successful option to obtain a deeper and painless sedation (Tab. 1). Their main advantage consists in a deep and painless sleep, maintaining the respiratory drive and active upper airway reflexes. Indeed, many case reports described a successful and safe use of dexmedetomidine and ketamine for procedural sedation, also when analgesia and autonomous ventilation are required [26, 28]. For this reason, their administration could be particularly safe when the maintenance of spontaneous ventilation is a priority, such as patients with cardiorespiratory comorbidities or high risk airway obstruction [19]. In addition, their pharmacological association may prevent each other's adverse events, having limited effects on respiratory function. Dexmedetomidine counteracts tachycardia, hypertension and emergence agitation from ketamine, while the latter prevents bradycardia and hypotension which has been reported with dexmedetomidine [29]. The most frequent drawbacks of the association are nausea and vomiting, preventable with ondansetron's administration, and a long recovery time.

Premedication with intranasal dexmedetomidine followed by intravenous ketamine may offer significant advantages, facilitating venous access in patients requiring painful procedures, in which the use of dexmedetomidine only could not guarantee an adequate level of pain control and sedation. 


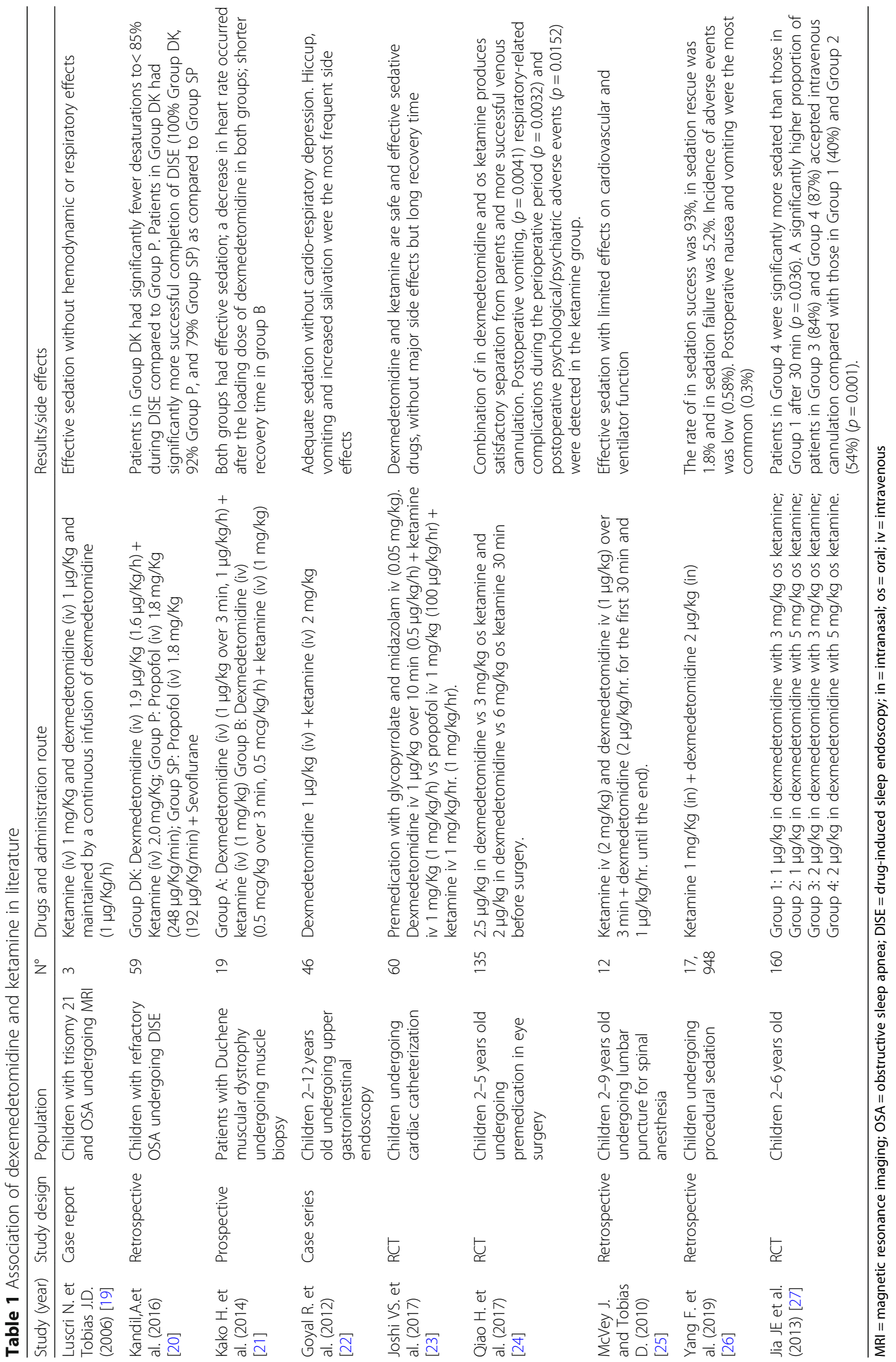




\section{Conclusion}

This is the first case described in literature in which a child with alpha-mannosidosis successfully underwent procedural sedation with intranasal dexmedetomidine and intravenous ketamine.

This case highlights the advantages of the association of intranasal dexmedetomidine followed by intravenous ketamine. Further prospective studies should follow this proof of concept.

\section{Abbreviations}

DISE: Drug-induced sleep endoscopy; DK: Dexmedetomine and ketamine; $\mathrm{EtCO}_{2}$ : End-tidal carbon dioxide; HR: Heart rate; In: Intranasal; Iv: Intravenous; MRI: Magnetic resonance imaging; Os: Oral; OSA: Obstructive sleep apnea; P: Propofol; SP: Propofol and sevoflurano; $\mathrm{SpO}_{2}$ : Oxygen saturation

\section{Acknowledgments}

We thank the patient and his parents for allowing us to publish this case report. We are also grateful to Caterina Barbi for the revision of the English text.

\section{Authors' contributions}

All authors listed on the manuscript has seen and approved the submission of this version of the manuscript and takes full responsibility for the manuscript. Matteo Trevisan, and Sara Romano wrote the first draft of the manuscript. Sara Romano, Matteo Trevisan and Irene Bruno followed clinically the patient. Flora Maria Murru performed the radiological imaging. Giorgio Cozzi and Egidio Barbi revised the manuscript and made substantial scientific contributions.

\section{Funding}

None of the authors received any honorarium, grant, or other form of payment for this study.

\section{Availability of data and materials \\ No supporting data are available.}

Ethics approval and consent to participate

Not applicable.

\section{Consent for publication}

The authors declare that we have obtained the written consent from the parents of the patient for publication of the photographs in all forms and media.

\section{Competing interests}

The authors declare that they have no competing interests.

\section{Author details}

${ }^{1}$ Department of Medicine, Surgery, and Health Sciences, University of Trieste, Trieste, Italy. ${ }^{2}$ Department of Radiology, Institute for Maternal and Child Health - IRCCS "Burlo Garofolo", Trieste, Italy. ${ }^{3}$ Department of Pediatrics, Institute for Maternal and Child Health - IRCCS "Burlo Garofolo", Trieste, Italy. Via dell'Istria 65/1, 34131 Trieste, Italy. ${ }^{4}$ Pediatric Emergency Department, Institute for Maternal and Child Health - IRCCS "Burlo Garofolo" - Trieste, Italy. Via dell'Istria 65/1, 34131 Trieste, Italy.

Received: 5 April 2019 Accepted: 22 August 2019 Published online: 03 September 2019

\section{References}

1. Pascolo P, Peri F, Montico M, et al. Needle-related pain and distress management during needle-related procedures in children with and without intellectual disability. Eur J Pediatr. 2018;177:1753-60.

2. Cozzi G, et al. Combination of intranasal dexmedetomidine and oral midazolam as sedation for pediatric MRI. Paediatr Anaesth. 2017;27:976-7.

3. Meikle PJ. Newborn screening for lysosomal storage disorders: clinical evaluation of a two-tier strategy. Pediatrics. 2004. https://doi.org/10.1542/ peds.2004-0583.
4. Lund AM, et al. Comprehensive long-term efficacy and safety of recombinant human alpha-mannosidase (velmanase alfa) treatment in patients with alpha-mannosidosis. J Inherit Metab Dis. 2018;41:1225-33.

5. Walker $\mathrm{R}$, et al. Anaesthesia and airway management in mucopolysaccharidosis. J Inherit Metab Dis. 2013;36:211-9.

6. Green SM, Roback MG, Kennedy RM, Krauss B. Clinical practice guideline for emergency department ketamine dissociative sedation: 2011 update. Ann Emerg Med. 2011;57:449-61.

7. Roback MG, Carlson DW, Babl FE, Kennedy RM. Update on pharmacological management of procedural sedation for children. Curr Opin Anaesthesiol. 2016;29:S21-35

8. Green SM, et al. Predictors of Airway and Respiratory Adverse Events With Ketamine Sedation in the Emergency Department: An Individual-Patient Data Meta-analysis of 8,282 Children. Ann Emerg Med. 2009;54:158-168.e4.

9. Brown $L$, et al. Adjunctive atropine is unnecessary during ketamine sedation in children. Acad Emerg Med. 2008;15:314-8.

10. Di Mascio A, Bossini B, Barbi E, Benini F, Cozzi G. Use of ketamine by paediatricians in Italian paediatric emergency departments: a missed opportunity? Eur J Pediatr. 2019:1-5. https://doi.org/10.1007/s00431-019-03320-z

11. Mahmoud M, Mason KP. Dexmedetomidine: review, update, and future considerations of paediatric perioperative and periprocedural applications and limitations. Br J Anaesth. 2015;115:171-82.

12. Ebert TJ, Hall JE, Barney JA, Uhrich TD, Colinco MD. The Effects of Increasing Plasma Concentrations of Dexmedetomidine in Humans. Anesthesiol J Am Soc Anesthesiol. 2000;93:382-94.

13. Yuen VM, et al. ORIGINAL ARTICLE: optimal timing for the administration of intranasal dexmedetomidine for premedication in children. Anaesthesia. 2010;65:922-9.

14. Subramanyam R, et al. To pretreat or not to pretreat. Anesth Analg. 2015; 121:479-85.

15. Ghai B, Jain K, Saxena AK, Bhatia N, Sodhi KS. Comparison of oral midazolam with intranasal dexmedetomidine premedication for children undergoing CT imaging: a randomized, double-blind, and controlled study. Pediatr Anesth. 2017;27:37-44

16. Peng K, Wu S, Ji F, Li J. Premedication with dexmedetomidine in pediatric patients: a systematic review and meta-analysis. Clinics (Sao Paulo). 2014;69: 777-86.

17. Cravero JP, et al. Incidence and Nature of Adverse Events During Pediatric Sedation/Anesthesia for Procedures Outside the Operating Room: Report From the Pediatric Sedation Research Consortium. Pediatrics. 2006;118:1087 LP-1096.

18. Cozzi G, Norbedo S, Barbi E. Intranasal Dexmedetomidine for procedural sedation in children, a suitable alternative to chloral hydrate. Pediatr Drugs. 2017;19:107-11.

19. Luscri N, Tobias JD. Monitored anesthesia care with a combination of ketamine and dexmedetomidine during magnetic resonance imaging in three children with trisomy 21 and obstructive sleep apnea. Paediatr Anaesth. 2006;16:782-6.

20. Kandil, A. et al. Comparison of the combination of dexmedetomidine and ketamine to propofol or propofol/sevoflurane for drug-induced sleep endoscopy in children. Pediatr. Anesth. 2016;26:742-751.

21. Kako $\mathrm{H}$, et al. Dexmedetomidine and ketamine sedation for muscle biopsies in patients with Duchenne muscular dystrophy. Pediatr Anesth. 2014;24:851-6.

22. Goyal R, Shukla RN, Patra AK, Bhargava DV, Singh S. Ketodex, a combination of dexmedetomidine and ketamine for upper gastrointestinal endoscopy in children: a preliminary report. J Anesth. 2012;27:461-3.

23. Joshi VS, Kollu SS, Sharma RM. Comparison of dexmedetomidine and ketamine versus propofol and ketamine for procedural sedation in children undergoing minor cardiac procedures in cardiac catheterization laboratory. Ann Card Anaesth. 2017;20:422-6.

24. Qiao H, Xie Z, Jia J. Pediatric premedication: a double-blind randomized trial of dexmedetomidine or ketamine alone versus a combination of dexmedetomidine and ketamine. BMC Anesthesiol. 2017;17:158.

25. McVey JD, Tobias JD. Dexmedetomidine and ketamine for sedation during spinal anesthesia in children. J Clin Anesth. 2010;22:538-45.

26. Yang F, et al. Analysis of 17948 pediatric patients undergoing procedural sedation with a combination of intranasal dexmedetomidine and ketamine. Pediatr Anesth. 2019;29:85-91.

27. Jia J-E, Chen J-Y, Hu X, Li W-X. A randomised study of intranasal dexmedetomidine and oral ketamine for premedication in children. Anaesthesia. 2013;68:944-9. 
28. Rozmiarek A, Corridore M, Tobias JD. Dexmedetomidine-ketamine sedation during bone marrow aspirate and biopsy in a patient with duchenne muscular dystrophy. Saudi J Anaesth. 2011;5:219-22.

29. Levanen J, Makela ML, Scheinin H. Dexmedetomidine premedication attenuates ketamine-induced Cardiostimulatory effects and Postanesthetic delirium. Anesthesiol J Am Soc Anesthesiol. 1995;82:1117-25.

\section{Publisher's Note}

Springer Nature remains neutral with regard to jurisdictional claims in published maps and institutional affiliations.

Ready to submit your research? Choose BMC and benefit from:

- fast, convenient online submission

- thorough peer review by experienced researchers in your field

- rapid publication on acceptance

- support for research data, including large and complex data types

- gold Open Access which fosters wider collaboration and increased citations

- maximum visibility for your research: over $100 \mathrm{M}$ website views per year

At BMC, research is always in progress.

Learn more biomedcentral.com/submissions 